América sin Nombre, n.o 21 (2016): 107-116

DOI: 10.14198/AMESN.2016.21.08

ISSN: 1577.3442 / eISSN: 1989-9831

Fecha de recepción: 20/10/2016

Fecha de aceptación: 20/11/2016
Puede citar este artículo como:

Poot Herrera, Sara. «Atrapados sin salida: de nuevo con Sor Juana en Los empeños de una casa». Teatro breve virreinal. Miguel Zugasti (coordinador). América sin Nombre, 21 (2016): 107-116, DOI: 10.14198/ AMESN.2016.21.08

Link para este artículo: http://dx.doi.org/10.14198/AMESN.2016.21.08

\title{
Atrapados sin salida: de nuevo con Sor Juana en Los empeños de una casa
}

\author{
No way out: once again with Sor Juana in The House of Desires
}

\author{
Sara Poot Herrera* \\ University of California, Santa Barbara \\ UC-Mexicanistas (Intercampus Research Program)
}

\section{Resumen}

Es tal la seducción de Los empeños de una casa de Sor Juana Inés de la Cruz, que una vez más volvemos a la lectura del texto y queremos saber más acerca de su primera representación. ¿Cuándo y cómo sería ésta? Las referencias al contexto histórico mencionadas en la comedia dieron pie a que se propusiera una fecha de representación; lo mismo su alusión en la propia obra a autores y personajes de otras comedias, que dio lugar a una fecha distinta. ¿Se ha resuelto lo relativo a la primera vez que se representó la comedia? Y debido a su larga extensión, ¿̇e representaría completa la primera vez que se llevó a cabo? Las piezas menores que acompañan a las tres jornadas de la comedia -una loa, tres canciones, dos sainetes y un sarao- ofrecen claves para situar la comedia en el contexto de la cartelera teatral de la época. Si bien no se resuelve plenamente lo relativo a la fecha de representación de la comedia, sí resulta clara su relación con otras dos comedias novohispanas puestas en escena en años cercanos. El tríptico teatral tiene en el centro Los empeños de una casa, y sus piezas menores son imprescindibles en el conjunto del festejo, espectacular y barroco.

Palabras clave: comedia, jornadas, loa, canciones, sainetes, sarao; texto, representación, piezas menores, festejo, tríptico, cartelera teatral.

\section{Abstract}

The seductiveness of The House of Desires (also translated as House of Trials) by Sor Juana Inés de la Cruz is so powerful that once again we feel compelled to return to the text wanting to know more about its first representation. How and when did it take place? References to the historical context mentioned in the play suggest a probable representation date,

* Profesora. University of California, Santa Bárbara. Áreas de especialización: Literatura colonial hispanoamericana (especialmente Sor Juana Inés de la Cruz y teatro novohispano) y Literatura mexicana contemporánea (en especial de los siglos xx y xxI).

Cofundadora y Directora de UC-Mexicanistas (Intercampus Research Program).

Miembro correspondiente por Mérida, Yucatán, de la Academia Mexicana de la Lengua.

Premios en los últimos dos años: Medalla de Oro del Festival Internacional Maya (FIC) 2016: "Mujer 2015" [Galardón Amees, Asociación Mexicana de Empresarias y Ejecutivas del Sureste; Medalla Forjadores de Cultura [Universidad Autónoma de Yucatán y la Feria Internacional de la Lectura Yucatán (FILEY) (2015); Medalla Eligio Ancona 2014 [Gobierno del Estado de Yucatán/ Universidad Autónoma de Yucatán]; Outstanding Graduate Mentor Award, UCSB (2013-2014).

Entre sus más recientes publicaciones, los libros: Viento, galope de agua. Entre palabras: Elena Poniatowska (2014); Sor Juana, de Neplanta a San Jerónimo (2014); De las ferias, la de Arreola es más hermosa (2013). 
but the mention of certain authors and characters from other plays in the same text suggests a different date. Is the first representation date of the comedy settled, then? Moreover, considering its extension, was it initially performed in full? The minor pieces accompanying the play's three stages - a playlet or loa, three songs, two verse plays, and a sarao- offer keys to locate Sor Juana's comedy within the context of the theatre season of the time. Even if the exact date of its first representation may never be definitively settled, its relation to another two Novohispanic plays -also performed during the 17th century- is clear. The theatrical triptych has Los empeños de una casa in its centre, and its minor pieces are essential to complete the spectacular and baroque celebration.

Keywords: comedy, play, theatrical performance, playlet (loa), songs, verse play, sarao; text, representation, minor plays, celebration, triptych, theatrical season.

\section{El concepto y sus accesorios}

Con Los empeños de una casa ${ }^{1}$, Sor Juana Inés de la Cruz tira la casa por la ventana y en un remake perfecto resignifica empeños clásicos que la anteceden. En el eje de las tres jornadas, donde reside el núcleo de la comedia, se prenden accesorios, piezas que acentúan el toque personal -el estilo- de quien la ha ideado: una loa, dos sainetes, tres canciones, un sarao. A la casa la sostienen sus cimientos -las tres jornadas-, y la visten, "la adornan», sus siete piezas menores ("prendas menores») que, sin ellas, el festejo no sería lo que es: un verdadero festín, barroco por excelencia y por añadidura de diez piezas. Estamos hablando de Los empeños de una casa, metida ésta en una cajita musical (loa, copla en un sainete, canciones, sarao) y en la caja de imprenta del Segundo volumen de las obras de Soror Juana Inés de la Cruz (1692).

1. Utilizo la edición facsimilar prologada por Margo Glantz (México: UNAM, 1995) del Segundo volumen de las obras de Soror Juana Inés de la Cruz. Sevilla: Imprenta de Tomás López de Haro, 1692 (pp. 461-532), junto con la de Alberto G. Salceda, Comedias, sainetes y prosa, vol. 4 de las Obras completas de Sor Juana Inés de la Cruz. México-Buenos Aires, 1957 (pp. 3-184). En esta edición, el Festejo de Los empeños de una casa consta de nueve cuadros y treinta y seis escenas, más las siete escenas de la loa. La jornada primera de esta "comedia famosa» tiene un cuadro y tres escenas (I, II, III), un segundo cuadro y una cuarta escena (IV) y un tercer cuadro y cuatro escenas más (V, VI, VII, VIII). La segunda, otro primer cuadro y dos escenas (I, II), un segundo cuadro y cinco escenas (III, IV, V, VI, VII) y un tercero con otras cinco escenas (VIII, IX, X, XI, XII). La jornada tercera, un primer cuadro y siete escenas (I, II, III, IV, V, VI, VII), un segundo cuadro y tres escenas (VIII, IX, X), un tercer cuadro y siete escenas más (XI, XII, XIII, XIV, XV, XVI). La organización sugiere un diseño de creación, y a primera vista da idea de la extensión de toda la obra.
Entre los censores del Segundo volumen de las obras de Sor Juana, donde se publicó Los empeños de una casa, el $\mathrm{R}^{\mathrm{mo}}$ Padre Maestro Juan Navarro Vélez opinó: «De las comedias, sólo diré, que me parecen dignas de hacer entre las más aplaudidas de los autores más primorosos en este género de poesía, y que en los teatros merecerán los aplausos que se granjean en el papel» (8). El punto de vista de don Ambrosio de la Cuesta fue: "Manifestando en todo [Sor Juana] aquella unión siempre difícil de saber hermanar lo elegante con lo sentencioso, lo suave con lo profundo y lo ameno con lo útil [...], o ya en lo cómico, uniendo singular erudición de humanas y divinas letras» (18). En un poema que en este volumen se le dedica, entre otros, don Juan Bautista Sandi de Vivre mencionó el influjo calderoniano en Sor Juana -de «Calderón sus autos y comedias» (77)-, y en su aprobación del volumen, Pedro Ignacio de Arce, regidor de la Villa de Madrid, comparó a la poeta novohispana con los clásicos y con lo más granado de los poetas del siglo de oro español; un ejemplo de similitudes, «las composiciones dialógicas a Calderón» (94). Estas opiniones, y otras más no citadas, eran de quienes en España leyeron Los empeños de una casa incluido en el Segundo volumen de las obras de Sor Juana que, como el primero, alcanzó a ser leído por su autora. De sus panegíricos dijo en un "romance que no se halló acabado": "iA una ignorante mujer / cuyo estudio no ha pasado / de ratos, a la precisa / ocupación mal hurtados [...] / se dirigen los elogios / de los ingenios más claros / que en púlpitos y escuelas / el mundo venera sabios?» La poeta ya no pudo leer estas letras impresas, publicadas en el tercer volumen de su obra en 1700, cinco años después de su muerte (Fama y obras pósthumas 158-159). En cambio sí vio en letras de molde los textos de su segundo libro editado y reeditado en España, así como algunas reediciones de Inundación Castálida (1689).

En el índice del Segundo volumen de las obras de Soror Juana Inés de la Cruz (Sevilla, 1692), donde 
se publica por primera vez Los empeños de una casa, sólo aparecen los títulos de las piezas menores (que no corresponden exactamente a como aparecen en los interiores del volumen). Así se indican:

—Loa de la Comedia: Los Empeños de una Casa (450).

—Letra, que empieza: Divina Lisi permite; y se cantó antes de la Comedia (460).

- Letra, que se cantó después de la primera Jornada, y empieza: Bellíssima María (478).

-Primero Sainete de Palacio (479).

-Letra, que empieza: Tierno Pimpollo hermoso, y se cantó al final de la segunda Jornada (499).

- Sainete segundo (500).

- Sarao al fin de la Comedia (526).

Aunque mencionado como punto de referencia, en el índice de esta edición antigua no aparece el título "Los empeños de una casa, / Comedia famosa» (que sí consta en el interior, p. 461), tampoco lo de Jornada primera (461-478), Jornada segunda (483-499) ni Jornada tercera $(505-525)^{2}$. Si al índice se atuviera un lector (nos consta que sí existen éstos, al menos hoy), sólo tendría la información de las siete piezas que, en este índice, explícitamente sustentan «lo que no aparece», aquello que es precisamente la «foundation» de la comedia: sus tres jornadas, el cuerpo de Los empeños. En cambio sí se registra el título, igual que las tres jornadas, en el índice de la edición moderna de 1957, donde leemos lo de «Festejo de Los empeños de una casa» (3), que tampoco está en la edición de 1692. Lo de "comedia famosa» aparece en una y otra edición (1692 y 1957). Lo es, pero ¿̇desde cuándo lo sería? No se dice lo mismo de Amor es más laberinto, que la antecede ${ }^{3}$.

En la edición de Sevilla ${ }^{4}$, y en el orden (aquí copiado), se publicaron las siete piezas menores que informan -lo que es importante- del orden de la representación de Los empeños. Respectivamente, las tres letras se cantaron (si es que se representó completo el festejo) antes de la comedia (¿enseguida de la loa la primera letra?), después de la primera

2. La primera jornada tiene 17 páginas; la segunda, 16; la tercera, 20.

3. Amor es más labyrinto, comedia, de la qual las jornadas primera y tercera son de la Madre Juana, y la segunda del Lic. D. Juan de Guevara, Ingenio conocido de la Ciudad de México (p. 389).

4. Los empeños de una casa cierra la sección de "Poesías cómicas», que a su vez cierra el Segundo volumen. jornada (¿antes del primer sainete la segunda?) y al final de la segunda jornada (¿antes del segundo sainete la tercera?). La loa, las tres canciones, el primer sainete y el sarao acentúan el carácter festivo y musical de la representación. Miguel Zugasti enfatiza en el uso de la música en las tres canciones, piezas líricas acompañadas de sonido instrumental, y lo conecta con la praxis escénica de España, con ejemplos paralelos de Tirso de Molina, Castillo Solórzano, Calderón de la Barca y Bances Candamo (1998). La loa funciona en el doble plano -el literal y el metafórico o alegórico-, al referirse como "Casa» a la Nueva España. Canta el Mérito: «Y pues esta Casa, / A quien iluminan / Tres Soles con rayos, / Una Alva con risa». Y canta la Dicha: "Y sea en su Casa, / Porque eterna viva, / Como la Nobleza, / Vínculo la Dicha». El festejo concluye cuando en el «Sarao de Quatro naciones», después de salir los espańoles, los negros, los italianos y los mexicanos, "Júntanse las Cuatro naciones y Tañen la Reyna, y cantan», $\mathrm{y}$ "Tocan los instrumentos el Turdión, y dançan». Una vez que canta el coro 4, canta el coro 3 cuando "Tocan los instrumentos la Jácara, y la dançan». La música, el coro y la danza del sarao llenan con plena alegría un escenario en el que las voces de la última pieza menor repiten una y otra vez el «hoy» ¿del festejo?, del gobierno, de la pareja virreinal y del «tierno Renuevo / el bello Joseph / Que siendo tan Grande, Espera crecer». La sensación de fiesta aún contagia la lectura, ¡365 años después de haber nacido su autora!

Al principio y fin del festejo de Los empeños de una casa se menciona la Casa (ya lo hemos visto en la loa) y la casa donde se lleva a cabo la comedia. Se canta en el sarao, "Dichosa esta casa merece besar» $\mathrm{y}$ "Porque el felize Dueño de esta casa». Estas menciones son bisagras que temáticamente aquí y allá integran el sentido de la comedia fundado en el espacio que se privilegia, la casa: Nueva España en lo mayúsculo y la casa de la celebración. Se menciona también el festejo, a los virreyes de la Laguna y a su hijo, nacido en México en julio de 1683. Lo de "festejo", que vimos ya que no está en el título de la edición de 1692 y sí en la de 1957, aparece mencionado textualmente en dos de las piezas menores de la comedia. En la loa, Acaso pide que no cesen los coros de repetir «Bienvenida sea / Tan sagrada Dicha, / Que la Dicha siempre / Es muy bienvenida». Así, el estribillo promete, asegura que «el festejo / Pare en alegría».

Cuando termina el sarao, y con él la comedia, el Coro 3 canta: 
Vuestra benignidad supla

la cortedad del festejo;

Pues su pequeñez disculpa

La improvisación del objecto.

$\mathrm{Y}$ en el ser vuestro también

Assegura los aciertos;

Pues nunca podrá ser corto,

Si se mira como vuestro. (532)

Las mismas piezas menores juegan (¿barrocamente?), contraponiéndose entre sí respecto a la extensión del conjunto: larga la comedia se dice en el segundo sainete, y corto el festejo se canta en el sarao. Lo largo se queda corto si de festejar a los de la Laguna se trata: el sarao armoniza temáticamente con las tres letras de la comedia, al referirse las cuatro piezas a la pareja virreinal, multiplicada con el nacimiento de Joseph, su hijo, «el mexicanito».

Al final de la loa (¿al editarse la pieza? si es que se editó posteriormente o al incorporar un suceso especial al final del poema) en voz de Todos se canta "Que con bien su Señoría / Ilustrísima haya entrado, / Pues, en su entrada festiva, / Fue la Dicha de su entrada, / La entrada de nuestra Dicha». El saludo regio y cortesano deviene saludo a la máxima autoridad de la Iglesia: a Francisco de Aguiar y Seixas, que el 4 de octubre de 1683 hizo su entrada pública a la Ciudad de México (Robles II, 56). Ese lunes los virreyes de la Laguna fueron a casa de don Fernando Deza. ¿Se puede seguir sosteniendo que ese día fue la representación de Los empeños de una casa de Sor Juana Inés de la Cruz como sugirió Alberto G. Salceda (1953; 1957, XVII-XX)? ¿O distinta fecha como sugirió antes Francisco Monterde (1945 y 1946)? ¿ O como propone Susana Hernández Araico más recientemente (1996)?

\section{2. ¿Y qué pasa con el «Sainete segundo» aún no mencionado?}

El segundo sainete, que abre un paréntesis entre la tercera letra y la tercera jornada, aporta el tono de humor (al igual que las tres jornadas de la obra larga, estas piezas tienen su costado gracioso), en el diálogo de dos personajes, actores de la comedia, que ponen en contexto la obra que se representa con la cartelera teatral de la época.

Este segundo sainete (como el primero, como la loa, las tres canciones y el sarao) es una pieza menor, adelanto secular, ¡y barroco!, de las formas breves contemporáneas de la literatura. Es, además, guiño inconfundible para la relación de Los empeños de una casa con otras dos comedias de la misma época: una, hecha a dos manos $-L a$ segunda Celestina, y nos referimos a la versión atribuida a Sor Juana - , la otra, prohibida por el Santo Oficio en el siglo XVII -El pregonero de Dios y patriarcha de los pobres, de Francisco de Acevedo. Vistas conjuntamente La segunda Celestina, El pregonero de Dios y Los empeños de una casa, se tiene una idea más precisa de sus fechas de representación en la capital de la Nueva España. De la única que se tiene el dato exacto de la fecha de su representación es de El pregonero: 4 de octubre de 1684 en el coliseo de México.

Veamos cómo se relacionan estas tres obras entre sí. Una vez «andadas» las dos primeras jornadas de Los empeños, tiene lugar el segundo sainete de la obra. Dos actores de la comedia aparecen en el escenario como si fueran (y lo son) actores de la compañía de teatro que tiene a su cargo la representación de Los empeños de una casa. Uno de ellos-Muñiz-dice que es mucho su cansancio y quiere, necesita descansar. Comenta:

Pues sobre estar molido, estoy tan seco

De aquestas dos Jornadas, que he pensado,

que en Mula de alquiler he caminado.

No es mejor acostarnos,

Y de aquessos cuydados apartarnos? (501)

El cansancio del otro -Arias, interlocutor de Muñizes menos importante que sus ansias de farfullar:

Y el murmurar, amigo, ay más desencanto?

Por lo menos a mí me haze provecho,

Porque las pudriciones, que en el pecho

Guardo, como veneno,

Salen quando murmuro, y quedo bueno. (501)

El sainete segundo ha comenzado, la sugerencia de Arias -su "catarsis»- se impone: "Aquí, Muñiz amigo, nos sentemos, / y toda la Comedia murmuremos» [p. 500]. ¿En qué consiste el diálogo de los dos protagonistas de este segundo sainete? Veamos: 1) Cuestionan la larga extensión de Los empeños. ¿Sólo de las dos jornadas que han corrido hasta ese momento?, ¿la longitud de éstas más las piezas menores que se intercalan?, ¿lo que falta de la comedia

5. Aquí no discutiremos la coautoría controversial del siglo $\mathrm{xx}$, asunto que ya tratamos en otra ocasión: Poot Herrera, 1996. 
incluyendo el segundo sainete que apenas inicia? Dicha largueza, aquí aludida, se contrapone a la cortedad del festejo mencionada en el sarao. En cuanto al festejo, en la "Loa, que precedió a la comedia, que se sigue», el Acaso (lo hemos visto) advirtió: "Y porque el festejo pare en alegría». Para este divertimento, son sustanciales las piezas menores de Los empeños, que mencionan dicho festejo, que lo llevan a cabo, que contagian con su alegría.

Además de la larga extensión de la comedia «criticada» en el segundo sainete, los comediantes mencionan también (¿indirectamente?) el lugar de la representación de Los empeños de una casa. Dice Muñiz:

\section{Quien sería}

El que al pobre de Deza engañaría

Con aquesta Comedia

Tan larga y sin traza? (501)

En caso de ser Fernando de Deza Ulloa, que es lo más seguro puesto que entre su genealogía es él quien en esa época tiene la función más importante en el gobierno virreinal, la autora de Los empeños da señales de su sentido del humor al llamarlo "pobre», a él, fiscal y contador general de tributos y azogues por esos años en la capital de la Nueva España. Y si es él el aludido, la comedia sería representada en su casa y de su esposa dońa Antonia Marcia de la Llana. Vivían en la antigua calle de la Profesa -hoy Madero- frente al antiguo Convento de San Francisco, testigo de acontecimientos varios en el siglo XVII.

Lo largo de las jornadas y el lugar donde se representan son motivo del diálogo del sainete segundo, así como la calidad de la comedia, que en su representación (todavía) no es "famosa", que apenas ese día la estrenan. ¿Lo sería ya cuando se publica en Sevilla en 1692? Su autora diría que no. El público en México oyó decir en el sainete lo que aquí leemos:

$\begin{array}{ll}\text { Arias } & \text { No veis, que por ser nueva } \\ \text { La han echado? } \\ \text { MuÑz Gentil prueba } \\ \text { de su bondad! } \\ \text { Arias } \\ \text { Aquessa es mi mohína. } \\ \text { No era mejor hazer a Celestina, } \\ \text { En que vos estuvisteis tan gracioso, } \\ \text { Que aun estoy temeroso, } \\ \text { Y es justo, que me assombre, } \\ \text { De que sois hechizera en trage de hombre? } \\ \text { (502) }\end{array}$

En el mismo sainete Arias y Muñiz relacionan la comedia que se está representando con otra anteriormente puesta en escena, y en la que participó, al menos, uno de los actores de Los empeños: Muñiz. Éste, vestido antes de hechicera y con la gracia (de su gracia, de actor travestido), pareciera que realmente es ahora cuando está disfrazado de hombre (y no cuando se disfrazó de mujer), y es lo que dice el propio interlocutor a quien el público allí presente lo habría entendido. La alusión directa es la infalible Celestina, lo que de inmediato se aclara por parte de quien hizo este papel:

\section{MuñIz Amigo, mejor era Celestina, En cuanto a ser Comedia ultramarina, Que siempre las de España son mejores, Y para digerirlas, los humores, Son ligeras, que nunca son pesadas Las cosas, que por agua están passadas.} (502)

Muñiz está de acuerdo. Era garantía presentar la comedia de Rojas, lo que no fue así, y aclara:

Pero la Celestina, que esta risa
Os causó, era Mestiza,
Y acabada a retazos,
Y si le faltó traza, tuvo trazos,
Y con diverso genio,
Se formó de vn Trapiche, y de vn Ingenio.
Y en fin, en su Poësía,
Por lo bueno, lo malo se suplía. (502)

La referencia está más clara que el agua (y así se ha visto por los estudiosos). Se trata de una Celestina "trasatlántica», representada antes en México, y se habla de la interpretación del personaje que hizo de hechicera. La relación es con La segunda Celestina, que se relaciona con uno de los textos a los que se refirió Juan Ignacio de Castorena y Ursúa en su edición en 1700 de la Fama y obras pósthumas: «un poema, que dejó sin acabar don Agustín de Salazar y perficionó con graciosa propriedad la poetisa» (fol. $* * 4 \mathrm{r})$.

Los actores del sainete de Los empeños se refieren (no podría ser de otra manera) a dicho "poema perficionado" por Sor Juana (representado antes) y con igual tono juguetón se van a referir a la autoría de la pieza que ahora se representa. El mismo actor, antes también de la Celestina, de pronto dice, y ya no refiriéndose a esta Celestina mestiza (que según él tenía «su chiste»), que no puede "Sufrir los disparates de 
Azevedo», y ¿cuáles son éstos? La comedia que ahora se representa: ¡Los empeños de una casa!

A los comentarios frente al público sobre 1) la extensión de Los empeños, 2) el lugar de la representación y 3) su relación con la Celestina mestiza antes puesta en escena posiblemente por la misma compañía teatral, y de seguro por uno de los dos comediantes del sainete, ahora 4) se juega con la autoría de la comedia de ese día.

Muñzz Pero aquí, vive Christo, que no puedo Sufrir los disparates de Azevedo.

Arias Pues es él el Autor?

MuñIZ Assi se ha dicho, Que de sv mal capricho La Comedia y los Sainetes han salido, Aunque es verdad, que yo no puedo creello. (502)

Muñiz dice que es verdad, aunque él no puede «creello». Se le atribuye a Azevedo, actor que aparece enseguida como (ficción sí), la autoría de Los empeños de una casa: Azev. "Ay silvado de mí! Ay desdichado! / Que la comedia, que hize, me han silvado» (503). Azevedo acepta ser el autor, ¿y sólo de la comedia y los sainetes? No se menciona la loa, las canciones ni el sarao, las otras piezas menores que rinden pleitesía a la familia virreinal. ¿Selección premeditada de su autora? Ella, ¿la autora de las finezas de la loa, las canciones y el sarao?, y Azevedo (en broma), ¿de las tres jornadas y los sainetes?, ¿de la parte cómica de Los empeños de una casa? Sor Juana se divierte pero seriamente clasifica. ¿Sugerencia la suya de una representación con dos tonos -loa, letras y sarao; sainetes y jornadas- de las que resulta el festejo completo?, ¿de una representación no de diez piezas sino de las tres jornadas y los dos sainetes, de las que es «autor» Azevedo? El intento de organizar de distintos modos las piezas enriquece las posibilidades de lectura de la comedia.

Este personaje (ficticio) representa en la realidad a Francisco de Acevedo, autor de El pregonero de Diosy patriarcha de los pobres, comedia que un día después de ser representada en el coliseo ( 4 de octubre) fue recogida por el Santo Oficio (5 de octubre). Eso fue en 1684. ¿Antes o después de la representación de Los empeños de una casa? Tenemos ya un triángulo de comedias, al que inicialmente siguieron sus líneas Francisco Monterde y Alberto G. Salceda, con dos propuestas distintas en cuanto a las fechas de representación de la comedia de Sor Juana; uno relacionó la obra con otra de época: El pregonero de Dios y patriarcha de los pobres; el otro, con la entrada oficial del nuevo arzobispo en México. Ambos son marcos de referencia para seguir indagando, sugiriendo, incluso imaginando, transfigurando la realidad. Fundamental, el texto escrito, las diez piezas de un festejo particular, celebrado en España en el proceso previo a su publicación: Los empeños de una casa de Sor Juana Inés de la Cruz. Su autora escribió pocas comedias, no asistió a corrales, tampoco a casas de comedia ni al coliseo, pero tenía el genio de la creación, el modelo de los clásicos, y sus empeños son muestra de dicha genialidad. Sus piezas menores, un despliegue prodigioso a todas luces.

\section{Teatro de tres pisos}

El segundo sainete de esta pieza mayúscula ha reunido una comedia controversial -La segunda Celestina-, otra que será clásica y famosa -Los empeños de una casa- y una comedia castigada -El pregonero de Dios y patriarcha de los pobres-. Cada una de ellas presenta problemas de distinta índole: de La segunda Celestina se discute el final atribuido a Sor Juana ${ }^{6}$; de Los empeños de una casa, la fecha de representación; de El pregonero de Dios y patriarcha de los pobres, su proceso inquisitorial. Relacionarlas de modo más profundo mostraría recurrencias de motivos y temas, semejanzas y diferencias de organización, de personajes; podría esclarecer algunas dudas intrínsecas a ellas y, a su vez, dar alguna información del estado de la cartelera teatral en México en dos décadas de la segunda mitad del siglo XVII; dicha cartelera es espejo de relaciones de poder de aquellos años en la Nueva España.

\section{4. «Los empeños de una casa», representada ¿en 1683?, ¿en 1684?, ¿cuándo?}

Retomando lo que se ha dicho respecto a la representación de Los empeños de una casa y relacionando una vez más esta comedia con El pregonero de Dios de Francisco de Acevedo, de nuevo citamos a Francisco Monterde $(1945,1946)$, quien propuso 1684 como año de escenificación de Los empeños de una casa. Alberto G. Salceda $(1953,1957)$ sugirió el lunes 4

6. Schmidhuber de la Mora no ha dejado de trabajar en su hallazgo relacionado con esta comedia (2015). Cotéjese también su opinión con Sabat de Rivers (1992). 
de octubre de 1683. Por una parte, la representación favorece la lectura del contexto en que se representó la comedia; por la otra, el texto escrito en su conjunto asegura su trascendencia, la genialidad de su armonía, es un modelo de perfección de festejos, de concepción de fiesta barroca.

Si se acepta lo que sugiere Salceda -4 de octubre de 1683-, la representación sería el día de la entrada pública del arzobispo a la ciudad de México, referencia que sí existe en la loa -sólo en la loa- que, se supone, antecede a la comedia. La entrada del arzobispo se consigna en el Diario de sucesos notables de Antonio de Robles, que no menciona ninguna comedia para ese día -lunes para mayor precisión-, pero sí que fueron los virreyes a casa del contador Deza ${ }^{7}$. Según Salceda -aunque no lo diga Robles-, el festejo sería en casa de Fernando Deza, espacio señalado en el segundo sainete de la comedia: « $i .$. Quién sería / el que al pobre de Deza engañaría / con aquesta comedia / tan larga y sin traza?» (501).

Miguel Zugasti (1998) y Aurelio González (1999) consideran brevemente la fecha de montaje y dan crédito a Susana Hernández Araico, quien opina que la obra pudo no representarse el 4 de octubre de 1683 sino entre el nacimiento del hijo de los virreyes y la celebración de su primer cumpleaños $(5$ de julio de 1683 - 5 de julio de 1684). En efecto, Hernández Araico (1996) sugiere que la comedia también podría haberse representado en agosto de 1684, ¿un mes después del primer cumpleaños del «mexicanito»?, a quien en su segundo año (julio de 1685) Sor Juana le dice en uno de sus romances (28) «por lo señorazo / vais, dejando lo señorito».

Aurelio González nos recuerda que Hernández Araico "ha propuesto que 'se considere seriamente la probabilidad de que los sainetes y el fin de fiesta que acompañan la loa, comedia y canciones en sus primeras ediciones españolas no lo hayan hecho realmente en su primera producción entre 1683-1684'” (Hernández Araico 122-123; González 124). De esta manera divide en dos el festejo: quedarían juntas la loa, la comedia y las tres canciones; fuera (en un principio), el primero y segundo sainete, y el sarao (fin de fiesta). Consideremos esta propuesta paso a paso. 1) En la loa se alude a la llegada del arzobispo y,

7. Robles, Diario, vol. 2, p. 56: «Entrada del señor Arzobispo. Lunes 4, día de nuestro padre San Francisco, hizo su entrada pública el señor arzobispo por el arco: asistieron los virreyes en casa del contador de tributos D. Fernando Deza; se colgaron los balcones de paño de corte de Flandes». Como vemos, no se consigna la representación de Los empeños de una casa. si la comedia no fue ese día -4 de octubre de 1683-, entonces no podría ir antes de la comedia (nos referimos a su representación). Habría loa, pero no comedia. ¿Será? 2) En el segundo sainete se menciona a Deza, luego esta pieza menor tendría que acompañar a la comedia. Si no, ¿cuál sería «aquesta comedia / tan larga y sin traza», mencionada por Muñiz en el sainete? No cabe duda de que el segundo sainete se refiere a Los empeños de una casa. La duda es cuándo se representarían las tres jornadas de la comedia que, empeñosamente, se resisten a su datación y si en un solo día se llevó a cabo completamente el festejo. ¿Sería así y cuándo?

\section{5. «La segunda Celestina», ¿ «El encanto es la hermosura y el hechizo sin hechizo»?}

Como hemos visto, en el segundo sainete de Los empeños de una casa, en el diálogo de dos actores de la compañía, hay señales acerca de la representación de una comedia que bien podría ser La segunda Celestina, título que corresponde también al de $E l$ encanto es la hermosura y el hechizo sin hechizo. Fue Salceda quien advirtió sobre la relación de esta comedia con Los empeños de una casa. Cuando en el mismo segundo sainete Arias le dice a Muñiz que estuvo muy gracioso en el papel de Celestina que representó anteriormente, Muñiz -actor que poco antes había dicho que era mejor ofrecer a Su Excelencia comedias de Calderón, Moreto o Rojas- aclara que en la ocasión aludida por Arias representó no a la Celestina clásica, sino a una Celestina resultado de un «trapiche [¿¿Sor Juana?], y de vn ingenio [Salazar y Torres]».

Sin ofrecer fuentes documentales, Armando de María y Campos $(1959,98)$ advierte de «una especie de segunda parte de La Celestina» que es la comedia El encanto es la hermosura y El hechizo sin hechizo, representada con otras obras de Agustín de Salazar y Torres -su autor- entre 1677 y 1679 en el Coliseo de México. Muerto Salazar y Torres, esta comedia, que había quedado inconclusa, tuvo dos finales distintos, uno de ellos atribuido a Sor Juana, que más se conoce como La segunda Celestina. ¿Se trata de la obra descubierta por Guillermo Schmidhuber en Filadelfia? ¿La representarían actores profesionales en el coliseo de México? ¿La misma compañía que ahora representa Los empeños de una casa? ¿La autora de Los empeños es coautora de La segunda Celestina mencionada en el segundo sainete? Podríamos responder afirmativamente a todas estas preguntas. Un 
dato más que resalta el rescate de esta comedia es su puesta en escena los días 26 y 27 de agosto de 2016 en Palacio Nacional de la Ciudad de México, a casi 340 años de su representación. Encontrar la documentación del primer dato afianzaría la relación de dos comedias relacionadas con Sor Juana Inés.

\section{6. «El pregonero de Dios y patriarcha de los pobres», debut y censura}

El pregonero de Dios y patriarcha de los pobres de Francisco de Acevedo fue representada el 4 de octubre de 1684 en el coliseo de la ciudad de México; Julio Jiménez Rueda la publicó en 1945 y Humberto Maldonado en 1992. Llama la atención la complejidad de la escenografía y de su representación. Trata de la vida «mundana» y conversión espiritual de San Francisco de Asís.

La obra empieza con una situación particular: «verse en empeño tal». De la alegría de la casa, pregonada con música y baile en la primera escena de la primera jornada, se pasa a las riñas y a los episodios bélicos contra los de Asís. Uno de los personajes es el demonio vestido de capitán. Éste, a pesar de sus largos parlamentos, no figura en el libreto de personajes. En la obra se crean irrealidades y visiones dentro de la irrealidad de la representación. En un proceso de altibajos, Francisco se convierte. Otro personaje también se convierte pero, al no resistir su elección conventual, se ahorca.

Un día después de su representación -el 5 de octubre de 1684- fuera del coliseo la Inquisición pidió la comedia a su director-Bartolomé de la Cueva- y prohibió totalmente la representación en el coliseo de El pregonero de Dios y patriarcha de los pobres de Francisco de Acevedo. En los legajos del proceso inquisitorial ${ }^{8}$ no figura quién denunció la comedia. Sí quién la dirigió. Azevedo (con 'z') aparece en el segundo sainete de Los empeños de una casa como si fuera su autor y va a ser castigado por "la mala hechura de la obra», incluso ésta se presta para leerse bajo sospecha de censura, por la que en realidad había pasado no Los empeños de una casa sino El pregonero de Dios y patriarcha de los pobres. El sainete alivia la situación y el escenario se llena de silbos y silbidos al imitar humorísticamente el modo de hablar de los españoles, de pronunciar la 's'.

8. Archivo General de la Nación: ABN [M], Inquisición, vol. 1508, exp. 8, fols. 166r-169r. Versión paleográfica.
En las tres obras reunidas en el segundo sainete de Los empeños de una casa vemos una clara línea de relación; sin embargo, aún no podemos fijar un punto definitivo sobre la fecha de representación de Los empeños de una casa. Su indefinición deja abierta la búsqueda, enriquecida en lo que va de ella.

\section{Nuevas lecturas de viejos documentos}

El miércoles 5 de julio de 1684, el Diario de Robles (II, 71) anota: «Fueron los años del hijo del virrey; hubo comedia en Palacio, y dio S.E. cuatro oficios y la compañía de Palacio a un criado suyo». Era el primer cumpleaños del niño y el virrey marqués de la Laguna ponía en manos de un criado la compañía teatral palaciega. Si Salceda tenía razón, Los empeños de una casa se habría representado nueve meses antes. Si Monterde, en 1684 y relacionaba Los empeños de Sor Juana con El pregonero de Acevedo. Hace pocos ańos, Hernández Araico sugirió que posiblemente entre julio - primer cumpleaños del hijo de los virreyes-y agosto de 1684, y la representación no cubrió el festejo completo. Ese 5 de julio de 1684, anotado por Robles, podría tener relación con la representación de Los empeños de una casa. ¿Y por qué no pensar en una fecha cercana a El pregonero de Dios y patriarcha de los pobres, representada, denunciada, recogida en su totalidad y prohibida por el Santo Oficio en octubre de 1684? El sainete de Los empeños de una casa sugiere la prohibición de la obra de Acevedo.

En concreto, no se sabe exactamente cuándo ni dónde se representó Los empeños de una casa. Si este dato puede o no ser fundamental, reconocemos que al performance del siglo del espectáculo virreinal novohispano aún le faltan piezas, nada menos que las de la gran comedia profana de la gran dramaturga del siglo XVII.

\section{Tríptico teatral}

Un aparte pero central y esto sí que es un sainete: antes de Los empeños de una casa seguramente se representó La segunda Celestina (¿1679?), quizás antes de El pregonero de Dios de Acevedo o, por qué no, quizás después (1684). Sor Juana debió conocer la obra de Acevedo al escribir su segundo sainete, y el público pudo reconocer al autor de El pregonero. Hay una relación estrecha entre las dos comedias, además de sus relaciones con otras comedias españolas. 
Azevedo, personaje de Los empeños, amenaza ahorcarse; el personaje de El pregonero de Acevedo se ahorca. Antes del "ahorcamiento" (llevado a cabo o no) Tacón, personaje de La segunda Celestina, amenaza también con ahorcarse. Le dice Celestina: "Avísame si te ahorcares / que yo pagaré el esparto» (Sor Juana Inés de la Cruz y Salazar y Torres, $L a$ segunda Celestina, 169). El segundo sainete de Los empeños y La segunda Celestina plantean un «ahorcamiento" que no se lleva a cabo y su tratamiento en cada caso no es nada grave sino lo contrario; no así el que le da Acevedo en El pregonero. Azevedo de Los empeños de una casa dice "denme garrote». "Dar garrote» es castigo inquisitorial. A Acevedo, autor de El pregonero, le dieron palo, si bien no garrote. ¿Sería antes o después de la presentación del segundo sainete de Sor Juana?, ¿¿de Los empeños?

Segundo aparte y sobre La segunda Celestina. Por si fuera poco, en 1681 en la ciudad de México dos lectores inquisitoriales, los dominicos Francisco Muñiz y Agustín Dorantes, en su informe sobre la revisión de libros solicitada por el Santo Oficio, nombraron una y otra vez un título, parte de una memoria de libros que requería censura (aprobatoria, reprobatoria, requerimiento de corrección), que aparecía como de Fernando de Rojas. El título, La segunda Celestina. Era parte de un inventario de libros del que presentaba la memoria la librería de Paula Benavides, viuda del impresor Bernardo Calderón. La ficha bibliográfica era «Fernando de Roxas, La segunda Celestina, Madrid, Imprenta de la viuda de Alonso Martín, 1632». Ninguna «segunda Celestina» (hay varias) es del autor de la "verdadera» (aunque así viniera en el libro), pero ¿por qué tanta atención por parte de los inquisidores a este título? Una y otra vez se pidió que se corrigiera hasta que finalmente el libro pasó la censura. Eso fue en 1681. Alrededor de los mismos años La segunda Celestina, iniciada por Agustín de Salazar y Torres ¿y concluida por Sor Juana?, se estaría representando en la Ciudad de México. Era la misma época del arco triunfal el Mercurio alegórico (1680) de Sor Juana Inés de la Cruz, lo que bien sabía Agustín Dorantes, cercano a su maestro, el Padre Antonio Núnez de Miranda, confesor de Sor Juana.

Pareciera que se trata de una comedia de enredos y de redes. En cuanto a las redes, no cabe duda de que estas tres comedias son de una casa de tres puertas. Casa con tres puertas difícil de representar. Mientras tanto, en la búsqueda de sus bisagras se sigue hablando, lucubrando, teorizando sobre estas piezas, más que nada acerca de Los empeños de una casa, pieza mayor del teatro lo mismo que sus piezas menores. Saber dónde, cuándo, cómo y quiénes representaron la loa, las letras, los sainetes, las jornadas y el sarao permitiría tallar más finamente este tríptico espectacular, inserto en el juego de intereses y fuerzas que diversificaban el ya en sí contradictorio siglo XVII.

\section{Bibliografía}

Acevedo, Francisco de. El pregonero de Dios y patriarca de los pobres. Julio Jiménez Rueda (ed.). México, Imprenta Universitaria, 1945.

AcEvedo, Francisco de. El pregonero de Dios y patriarca de los pobres. Humberto Maldonado Macías (ed.). La teatralidad criolla del siglo XVII. México: CONACULTA, 1992: 117-167.

Castorena y Ursúa, Juan Ignacio de. «Prólogo a quien leyere». Fama y obras pósthumas del Fénix de México, Décima Musa, poetisa americana, Sor Juana Inés de la Cruz. Madrid: Manuel Ruiz de Murga, 1700.

González, Aurelio. "Construcción teatral del festejo barroco: Los empeños de una casa de Sor Juana». Anales de Literatura Española, 13 (1999): 117-126.

Hernández Araico, Susana. «Problemas de fecha y montaje en Los empeños de una casa de Sor Juana Inés de la Cruz». Ysla Campbell (ed.). El escritor y la escena $I V$. Estudios sobre teatro español de los Siglos de Oro. Homenaje a Alfredo Hermenegildo. Ciudad Juárez: Universidad Autónoma de Ciudad Juárez, 1996: 111-123.

Juana Inés de la Cruz, Sor. Inundación Castálida de la única poetisa, musa décima, Soror Juana Inés de la Cruz. Madrid: Juan García Infanzón, 1689.

Juana Inés de la CRuz, Sor. Los empeños de una casa. Alberto G. Salceda (ed.). Obras completas. Vol. IV. Comedias, sainetes y prosa. México: Fondo de Cultura Económica, 1957: 3-184.

JuANa InÉs De La CRUZ, Sor. Los empeños de una casa. Margo Glantz (ed. facsímil y prólogo). Segundo volumen de las obras de Soror Juana Inés de la Cruz. Sevilla: Imprenta de Tomás López de Haro, 1692: 461-532.

Juana Inés de la Cruz, Sor. Fama y obras pósthumas del Fénix de México, Décima Musa, poetisa americana, Sor Juana Inés de la Cruz. Madrid: Manuel Ruiz de Murga, 1700.

Juana Inés de la Cruz, Sor, y Salazar y Torres, Agustín de. La segunda Celestina. Una comedia perdida de Sor Juana. Octavio Paz (presentación). Guillermo Schmidhuber de la Mora (ed.). México: Vuelta, 1990. 
María y Campos, Armando de. Guía de representaciones teatrales en la Nueva España (siglos XVI al XVIII). México: Costa-Amic, 1959.

Monterde, Francisco. "Primera presentación de Los empeños de una casa». Occidente, II, 6 (1945): 31-36.

Monterde, Francisco. «El Sainete de Palacio, flor del teatro profano de Sor Juana Inés de la Cruz». El hijo pródigo, XI, 35 (1946): 85-87.

Poot Herrera, Sara. «La segunda Celestina, ¿de Salazar y Torres y Sor Juana?» Agustín de la Granja y Juan Antonio Martínez Berbel (eds.). Mira de Amescua en candelero. Actas del Congreso Internacional sobre Mira de Amescua y el teatro español del siglo XVII. Granada: Universidad de Granada, 1996: 386-405.

Robles, Antonio de. Diario de sucesos notables (16651703). 2 vols. Antonio Castro Leal (ed.). México: Porrúa, 1972, 2a ed.

SABAT DE Rivers, Georgina. «Los problemas de La segunda Celestina». Nueva Revista de Filología Hispánica, 40.1 (1992): 493-512.
Salceda, Alberto G. "Cronología del teatro de Sor Juana». Ábside, 17 (1953): 333-341.

SalCedA, Alberto G. "Cronología de los festejos». Juana Inés de la Cruz, Sor. Obras completas. Vol. IV. Comedias, sainetes y prosa. México: Fondo de Cultura Económica, 1957: XVII-XX.

Schmidhuber de la Mora, Guillermo. "La segunda Celestina, la comedia perdida de Sor Juana, a veinticinco años de su descubrimiento». Sincronía, 68 (2015): 173-182.

Zugasti, Miguel. «El festejo para Los empeños de una casa de Sor Juana Inés de la Cruz en su contexto espectacular barroco». Carmen Beatriz López-Portillo (coord.). Sor Juana y su Mundo: una Mirada Actual. Memorias del Congreso Internacional. México: Universidad del Claustro de Sor Juana-UNESCO-Fondo de Cultura Económica, 1998: 468-476. 